\title{
Peroxyester Decarboxylation Studied by Picosecond Transient IR Spectroscopy
}

\author{
J. Aschenbriicker, ${ }^{\dagger}$ M. Buback, ${ }^{*}, \dagger$ N. P. Ernsting, ${ }^{\ddagger}$ J. Schroeder, ${ }^{\dagger}$ and U. Steegmiiller ${ }^{\dagger}$ \\ Institut für Physikalische Chemie der Universität Göttingen, Tammannstrasse 6, 37077 Göttingen, Germany, \\ and Institut für Physikalische und Theoretische Chemie der Humboldt-Universität zu Berlin, Bunsenstrasse 1, \\ 10117 Berlin, Germany
}

Received: November 12, 1997; In Final Form: May 19, 1998

The decarboxylation of tert-butyl-9-methylfluorene-9-percarboxylate is investigated by picosecond UV pump/ IR probe spectroscopy. An intense $308 \mathrm{~nm}$ UV pulse of 1 ps duration is used for excitation. The formation of $\mathrm{CO}_{2}$ is monitored on a picosecond time scale via the absorption of the asymmetric stretch at $2335 \mathrm{~cm}^{-1}$. The mode of bond scission, concerted or stepwise, is discussed.

\section{Introduction}

Because of their relatively weak $\mathrm{O}-\mathrm{O}$ linkage, organic peroxyesters are extensively used as initiators in free-radical polymerizations. ${ }^{1-3}$ Thermally or photochemically induced dissociation, e.g., of tert-butyl peroxyesters, $\mathrm{R}-\mathrm{C}(\mathrm{O}) \mathrm{O}-\mathrm{O} t \mathrm{Bu}$, may lead to different intermediates, depending on the mode of bond scission: (1) breakage of the $\mathrm{O}-\mathrm{O}$ bond and (2) simultaneous scission of the $\mathrm{O}-\mathrm{O}$ bond and $\mathrm{R}-\mathrm{C}$ bond., ${ }^{4,5}$ Whereas both mechanisms yield tert-butoxy radicals in the primary kinetic step, the decomposition according to (1) yields an intermediate acyloxy radical $\mathrm{R}-\mathrm{C}(\mathrm{O}) \mathrm{O} \cdot$, which may further decompose into an alkyl radical $\mathrm{R} \cdot$ and $\mathrm{CO}_{2}$. The simultaneous (concerted) process yields $\mathrm{R} \cdot, \mathrm{CO}_{2}$, and $t \mathrm{BuO} \cdot$ in a single step. In addition to an appreciable academic interest in understanding the mechanism of such unimolecular processes, the mode of decomposition, single-bond or two-bond scission, may result in enormous consequences for initiator efficiency and for the transfer activity of primary initiator-derived free radicals: cage recombination subsequent to (1) restores the peroxide, whereas recombination in (2) yields an ether, which under typical polymerization conditions may not dissociate to yield radicals. The differences in transfer activity, e.g., to polymers, are a consequence of (1) producing an oxygen-centered free-radical and (2) a carbon-centered free radical. (This argument neglects the fate of the $t \mathrm{BuO} \cdot$ radical that is formed in both cases.)

The mechanism is determined by the structure of the peroxide compounds and in particular by the stability of their radical intermediates. It is suggested that thermal decomposition of tert-butyl peroxyesters occurs by concerted bond cleavage if a highly stable radical may be formed. ${ }^{4}$ The solvent viscosity dependence, ${ }^{6}$ secondary deuterium isotope effects, ${ }^{7}$ and pressure dependence ${ }^{8}$ of thermal decomposition rates support this assumption for a series of tert-butyl peroxyesters, such as tertbutyl diphenylperacetate, tert-butyl $p$-methoxyphenylperacetate, and tert-butyl $p$-methylphenylperacetate. However, intermediate aroyloxy radicals were observed following laser flash photolysis of, e.g., tert-butyl peroxyesters $\mathrm{R}-\mathrm{C}(\mathrm{O}) \mathrm{O}-\mathrm{O} t \mathrm{Bu}$, with $\mathrm{R}=$ phenyl $^{9}$ and 9-methylfluorene. ${ }^{10}$

To distinguish between mechanisms 1 and 2, we decided to directly measure the formation of $\mathrm{CO}_{2}$ on a picosecond time

\footnotetext{
* To whom correspondence should be addressed.

$\dagger$ Universität Göttingen.

$\doteqdot$ Humboldt-Universität zu Berlin.
}

\section{SCHEME 1}

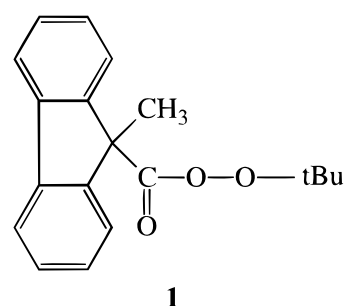

scale. In this Letter we report first results from this approach for tert-butyl-9-methylfluorene-9-percarboxylate, 1 (MeFlC $(\mathrm{O})$ $\mathrm{OO} t \mathrm{Bu}$, Scheme 1).

The two mechanisms, (1) and (2), read

$$
\begin{aligned}
& \mathrm{MeFlC}(\mathrm{O}) \mathrm{OO} t \mathrm{Bu} \stackrel{h v}{\longrightarrow} \mathrm{MeFlC}(\mathrm{O}) \mathrm{O} \cdot+\cdot \mathrm{O} t \mathrm{Bu} \stackrel{k T}{\longrightarrow} \\
& \mathrm{MeFl} \cdot+\mathrm{CO}_{2}+\cdot \mathrm{O} t \mathrm{Bu}
\end{aligned}
$$

and

$$
\mathrm{MeFlC}(\mathrm{O}) \mathrm{OO} t \mathrm{Bu} \stackrel{h v}{\longrightarrow} \mathrm{MeFl} \cdot+\mathrm{CO}_{2}+\cdot \mathrm{O} t \mathrm{Bu}
$$

respectively.

Picosecond laser flash photolysis studies on $\mathbf{1}$ with a time resolution of 25 ps have already been carried out by Falvey and Schuster. ${ }^{10}$ Following excitation at $266 \mathrm{~nm}$, they observed a transient absorption change at $488 \mathrm{~nm}$ with a rise time of 55 ps, which was attributed to the $\mathrm{MeFl} \cdot$ radical. The authors conclude that the peroxyester $\mathbf{1}$ decays in a consecutive way with $\mathrm{MeFlC}(\mathrm{O}) \mathrm{O} \cdot$ as a short-lived intermediate, which decarboxylates with a rate constant of $1.8 \times 10^{10} \mathrm{~s}^{-1}$. The lifetime of the intermediate, which is extremely short compared to about $0.2 \mu$ s for naphthoyloxy and benzoyloxy radicals in $\mathrm{CCl}_{4},{ }^{11}$ was assigned by the authors to the high stability of the carboncentered methylfluorenyl radical.

Time-resolved studies of organic peroxyester and diacyl peroxide decomposition in solution usually employ UV/VIS spectroscopy to identify the radical intermediates during the decarboxylation process. ${ }^{9,12,13}$ Because of broad and overlapping absorption bands in the visible range, the interpretation of these transient spectra is sometimes rather difficult. The infrared range, where characteristic narrow bands occur even in solution, is much better suited to identify and to quantify species. 


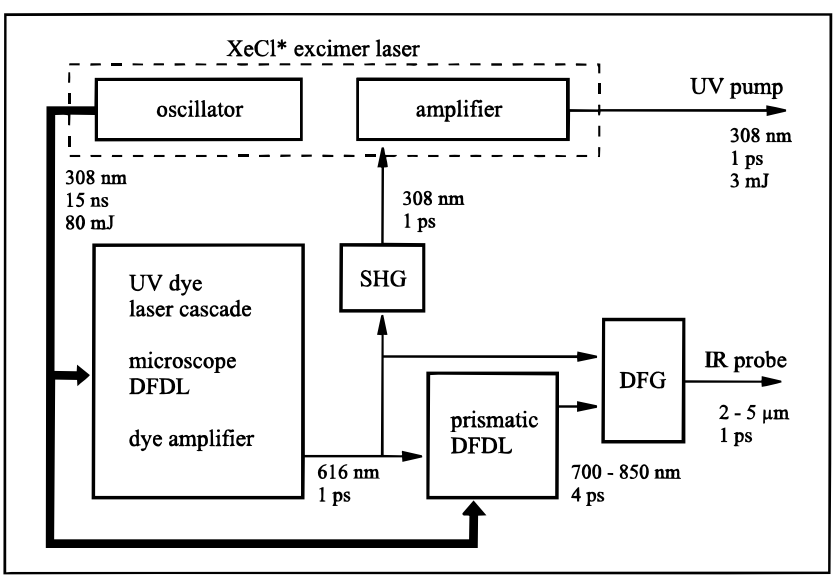

Figure 1. Schematic view of the UV/IR picosecond laser system. DFDL, distributed feedback dye laser; SHG, second harmonic generation; DFG, difference frequency generation.

Disadvantages of quantitative IR spectroscopy are due to the significantly lower oscillator strength of vibrational transitions compared to electronic transitions, which in turn requires a high sensitivity of the experimental setup. Instead of monitoring radical intermediates, we decided to measure the formation of the photoproduct $\mathrm{CO}_{2}$ by picosecond time-resolved infrared spectroscopy. The time evolution of the $\mathrm{CO}_{2}$ concentration should indicate whether the peroxyester decomposition occurs in a concerted or in a stepwise manner. Analysis via $\mathrm{CO}_{2}$ is advantageous as the band of the asymmetric stretch $\left(v_{3}\right)$ around $2335 \mathrm{~cm}^{-1}$ is well-separated from the peroxide and free-radical infrared bands. The spectral position of the carbonyl stretching mode of the acyloxy free radical is not known. However, one certainly would not expect that this absorption is shifted by more than $500 \mathrm{~cm}^{-1}$ from the peroxide carbonyl band located at 1769 $\mathrm{cm}^{-1} .{ }^{14}$ The extinction coefficient of the $\mathrm{CO}_{2} v_{3}$-mode in solution is fairly large, above $10^{3} \mathrm{M}^{-1} \mathrm{~cm}^{-1} .15$ Another advantage of time-resolved $\mathrm{CO}_{2}$ analysis is that the decarboxylation of various peroxides can be investigated with the same procedure and experimental setup, without adjusting the probe wavelength to absorption modes of varying radical intermediates. To the best of our knowledge, no picosecond measurement of the $\mathrm{CO}_{2}$ formation in decarboxylation reactions has been reported so far.

\section{Experimental Section}

The experimental setup is based on a picosecond dye laser system, which generates intense UV pump pulses at $308 \mathrm{~nm}$ and IR probe pulses that may be tuned between 2000 and 4300 $\mathrm{cm}^{-1}$ (see Figure 1).

The design of our picosecond dye laser system and of the difference frequency generation is described in detail elsewhere. ${ }^{16}$ Briefly, an excimer laser pumped cascade dye laser system with a distributed feedback dye laser (DFDL) ${ }^{17}$ provides $616 \mathrm{~nm}$ pulses of $1 \mathrm{ps}$ pulse duration and $100 \mu \mathrm{J}$ pulse energy. Part of this pulse is frequency-doubled and then used as a seed pulse for double-pass amplification in a second excimer laser tube. The pulse energy is amplified to typically $3 \mathrm{~mJ}$. The remainder of the $616 \mathrm{~nm}$ pulse is split into two parts: $20 \%$ are used to pump a prismatic DFDL for generating signal pulses, and the other part serves as the pump pulse for difference frequency mixing. A tunable prismatic DFDL is designed for optical pumping at $616 \mathrm{~nm} \cdot{ }^{18,19}$ With different dye solutions, the spectral range between 700 and $840 \mathrm{~nm}$ can be covered. The signal pulses are mixed with the remainder of the pump pulse at $616 \mathrm{~nm}$ in a $5 \mathrm{~mm}$ thick $\mathrm{LiIO}_{3}$ crystal. The resulting IR pulses at the difference frequency have a spectral bandwidth of $21 \mathrm{~cm}^{-1}$ and a pulse duration of $1.3 \mathrm{ps}$. The IR pulses are continuously tunable between 2000 and $2500 \mathrm{~cm}^{-1}$ by adjusting simultaneously the phase-matching angle and the signal wavelength. A germanium plate splits the IR beam into a probe and a reference part with equal pulse energies. Each of the infrared beams passes a flow cell with a path length of $12 \mathrm{~mm}$.

To achieve a good signal-to-noise ratio and to take advantage of the high pump power, we apply a traveling-wave arrangement. Because of its flat energy profile, the $308 \mathrm{~nm}$ pump pulse is well-suited for this technique. In the traveling wave geometry, the pump and probe beams overlap at a right angle. The temporal delay between the pump and the probe pulse is adjusted by a computer-controlled translation stage. To maintain the picosecond time resolution, the pulse front of the pump beam has to be inclined to match the group velocity of the probe beam in the solution. By means of a grating $\left(3600 \mathrm{~mm}^{-1}\right)$, the pulse front is tilted to an angle of $59^{\circ}$ and focused with a cylindrical lens to an area of $12 \mathrm{~mm} \times 1 \mathrm{~mm}$. It enters the fused silica front window of the sample cell and spatially overlaps with the IR beam just behind the window. Behind the cells, probe and reference infrared beams are focused with $\mathrm{CaF}_{2}$ lenses onto InSb detectors. The electronic signals are amplified, digitized, and handled by a computer. Each data point of an absorbancetime profile contains averaged data from typically 100 individual shots. Compared to a collinear setup, the traveling-wave arrangement enhances the signal by a factor of $8-10$. The signal-to-noise level is sufficient to detect changes in absorbance (optical density) of $\triangle \mathrm{OD}=0.001$. By bleaching the groundstate NCO-stretching mode of 1-naphthyl isocyanate at 2275 $\mathrm{cm}^{-1}$ after UV excitation, we determined the time resolution of the apparatus to be $1.8 \mathrm{ps}$.

The peroxide sample was provided by AKZO NOBEL (purity $>99 \%$ ). Measurements were performed in $\mathrm{CCl}_{4}$ (MERCK Uvasol) solution at room temperature. Even at the fairly long path length $(12 \mathrm{~mm})$, this solvent is transparent in the spectral range between 2000 and $2400 \mathrm{~cm}^{-1}$. All experiments were carried out at a peroxide concentration of $0.01 \mathrm{M}$, which is associated with an UV absorbance of $\mathrm{OD}(308 \mathrm{~nm})=1$ for a path length of $1 \mathrm{~mm}$.

\section{Results}

Figure $2 \mathrm{a}$ shows transient IR spectra for wavenumbers between 2100 and $2400 \mathrm{~cm}^{-1}$ obtained after UV excitation of $\mathbf{1}$ at time delays of $-5,20,100$, and 550 ps between the UV pump and the IR probe pulse. With increasing delay time, the maximum of the broad absorption contour is shifted to higher frequencies and the band narrows substantially. At $550 \mathrm{ps,}$ which is the longest delay time of our translation stage, the band maximum is located at $2330 \mathrm{~cm}^{-1}$. This transient spectrum may be compared with a stationary spectrum of $\mathrm{CO}_{2}$ dissolved in $\mathrm{CCl}_{4}$ (Figure 2b), which was obtained by bubbling $\mathrm{CO}_{2}$ through the solvent and recording the IR absorption with our picosecond infrared device.

The observed spectral width is a convolution of the $\mathrm{CO}_{2}$ stretching band in $\mathrm{CCl}_{4}$ (half width of $10 \mathrm{~cm}^{-1}$ as measured with an FTIR spectrometer) and the IR pulse bandwidth of 21 $\mathrm{cm}^{-1}$. There is a clear correspondence between the stationary spectrum and the transient infrared spectra at long delay times. Thus the transient IR absorption band can be safely assigned to the $\mathrm{CO}_{2}$ asymmetric stretch. The time evolution of the $\mathrm{CO}_{2}$ absorbance on the picosecond time scale is accompanied by 


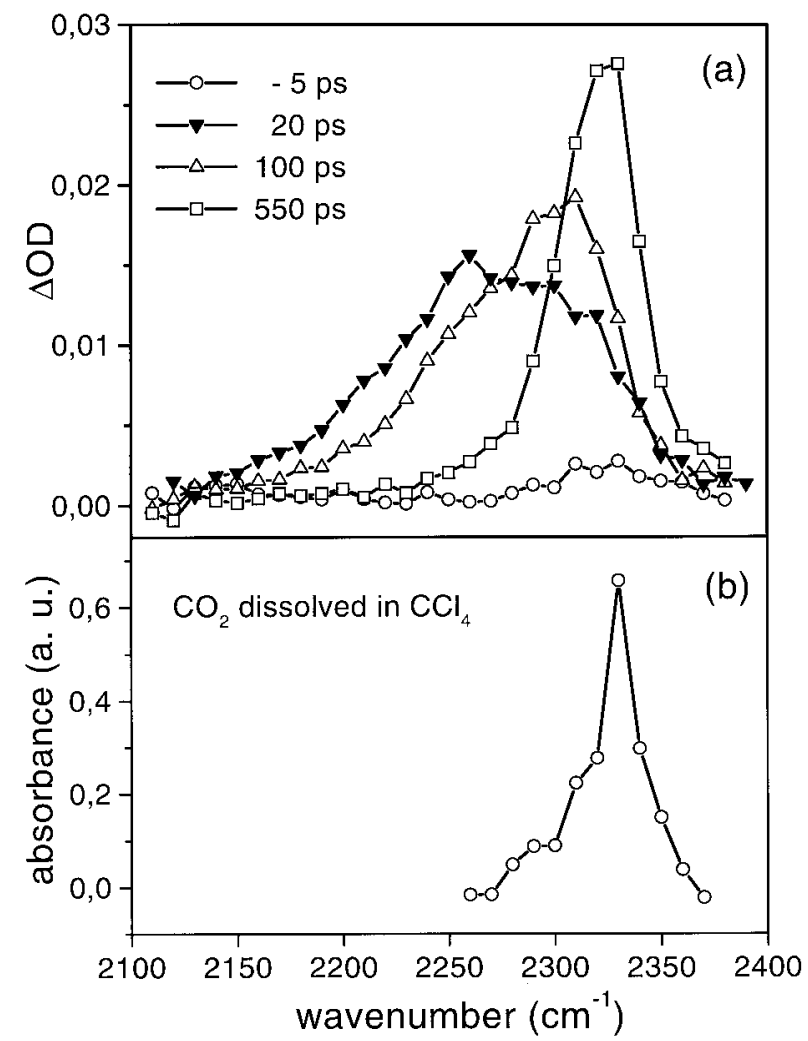

Figure 2. (a) Transient infrared spectra following UV excitation at $308 \mathrm{~nm}$ of 1 at delay times of $-5,20,100$, and $550 \mathrm{ps}$. (b) Stationary infrared spectra of gaseous $\mathrm{CO}_{2}$ dissolved in $\mathrm{CCl}_{4}$ measured with the picosecond IR assembly.

shifting and narrowing. To demonstrate this development, transient spectra at delay intervals of $50 \mathrm{ps}$ are presented in Figure 3.

Kinetic traces at two frequencies, 2260 and $2330 \mathrm{~cm}^{-1}$, are shown in Figure 4 together with single-exponential fits of the signals including convolution with the UV/IR cross-correlation function. At both wavenumbers an instantaneous rise in absorption occurs, where "instantaneous" refers to the time resolution of about $1.8 \mathrm{ps}$ for this particular setup. After this rise, at $2260 \mathrm{~cm}^{-1}$ a monotonic decay in optical density is observed, which can be fitted by a single-exponential function with a time constant of $177 \pm 5$ ps.

At $2330 \mathrm{~cm}^{-1}$, after the instantaneous rise in optical density, the signal continues to increase with a time constant of $206 \pm$ $18 \mathrm{ps}$. The instantaneous amplitude of the signal at $2330 \mathrm{~cm}^{-1}$ amounts to almost $50 \%$ of the absorbance change reached after $550 \mathrm{ps}$.

\section{Discussion}

The time-resolved measurement of the $\mathrm{CO}_{2}$ absorption should give insight into the mechanism of peroxide photodecomposition. However, the detailed kinetics are not directly accessible from the picosecond traces measured at selected frequencies. Owing to spectral shifting and narrowing, the absorbance change at the $\mathrm{CO}_{2}$ absorption band maximum around $2330 \mathrm{~cm}^{-1}$ is not linearly related to the amount of $\mathrm{CO}_{2}$ formed during the decarboxylation. The temporal and spectral evolution of transient $\mathrm{CO}_{2}$ absorption is assumed to be strongly influenced by vibrational cooling of "hot" $\mathrm{CO}_{2}$ by the surrounding solvent. The transient spectra in Figure 3 are in close agreement with IR spectra of hot $\mathrm{CO}_{2}$ produced in shock waves ${ }^{20}$ heated gas cells, ${ }^{21}$ and supersonic burners. ${ }^{22}$ To avoid problems associated

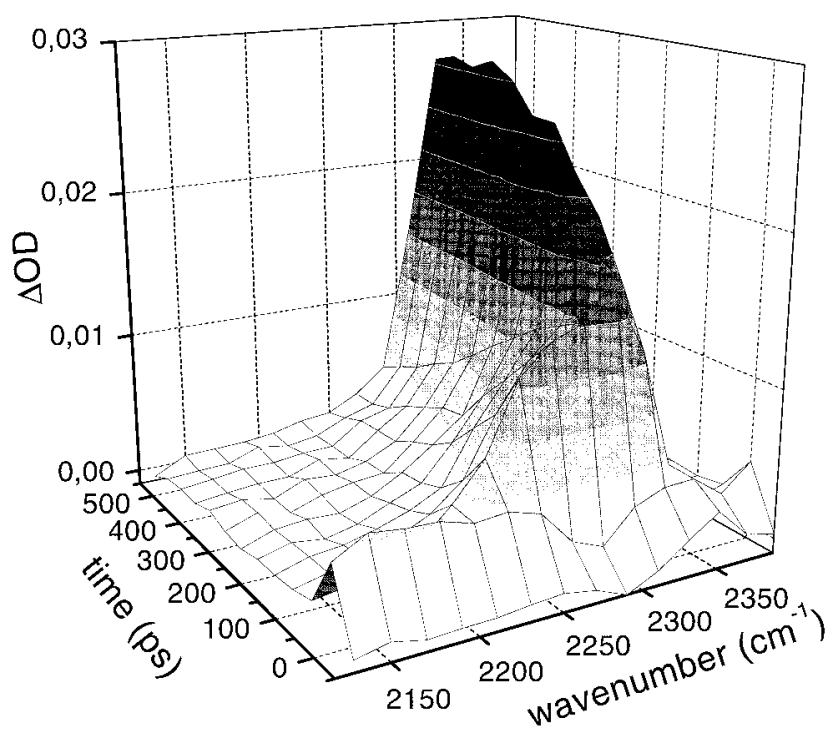

Figure 3. Spectral and temporal evolution of the IR absorbance of $\mathrm{CO}_{2}$ produced in the photodecarboxylation of $\mathbf{1}$.

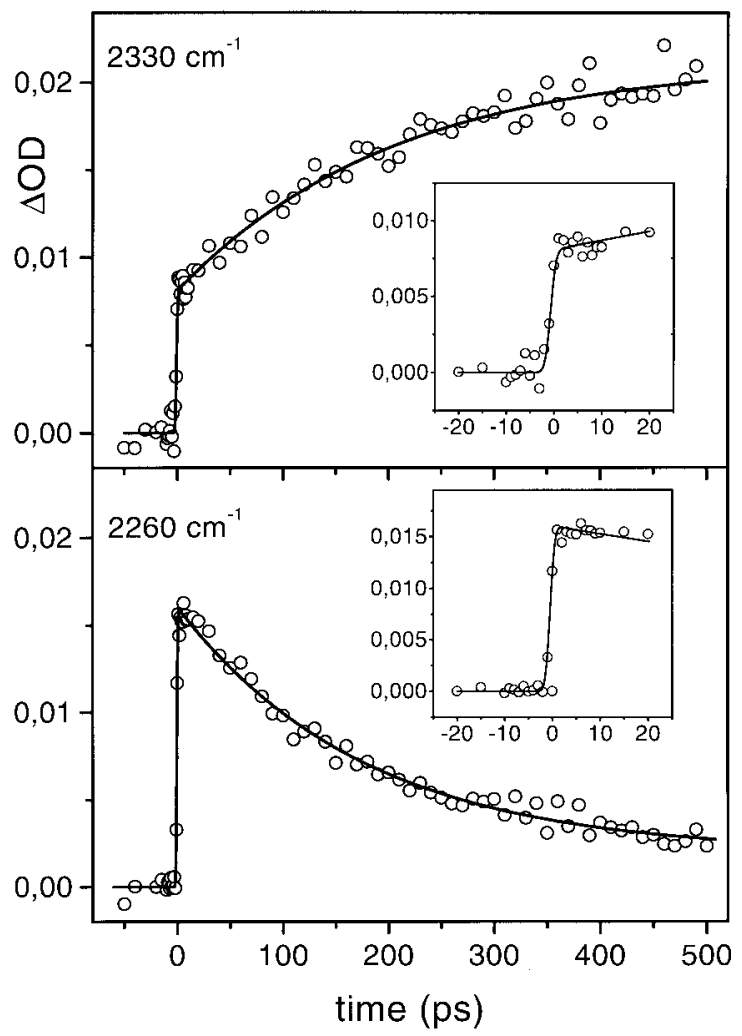

Figure 4. Kinetic traces and convoluted single-exponential fits taken at two spectral positions, 2260 and $2330 \mathrm{~cm}^{-1}$, during the decomposition of $\mathbf{1}$. The time constants for the decay at $2260 \mathrm{~cm}^{-1}$ and for the rise at $2330 \mathrm{~cm}^{-1}$ are 177 and $206 \mathrm{ps}$, respectively.

with the quantitative analysis of the cooling process of hot $\mathrm{CO}_{2}$, rather than considering molar absorption coefficients $\epsilon(v)$ at selected frequencies, the integrated absorption coefficient (vibrational intensity) $B=\int \epsilon(v) \mathrm{d} v$ is taken as a measure of $\mathrm{CO}_{2}$ concentration. In contrast to $\epsilon(v), B$ should be only weakly temperature-dependent. Up to $500 \mathrm{~K}, B$ has been found to be independent of temperature for several modes in pure $\mathrm{CO}_{2} \cdot{ }^{23,24}$ The integrated absorbance has been determined from the area below the measured transient spectra (Figure 2a) in the wavenumber range from 2100 to $2400 \mathrm{~cm}^{-1}$ at different time delays. The results are shown in Figure 5. 


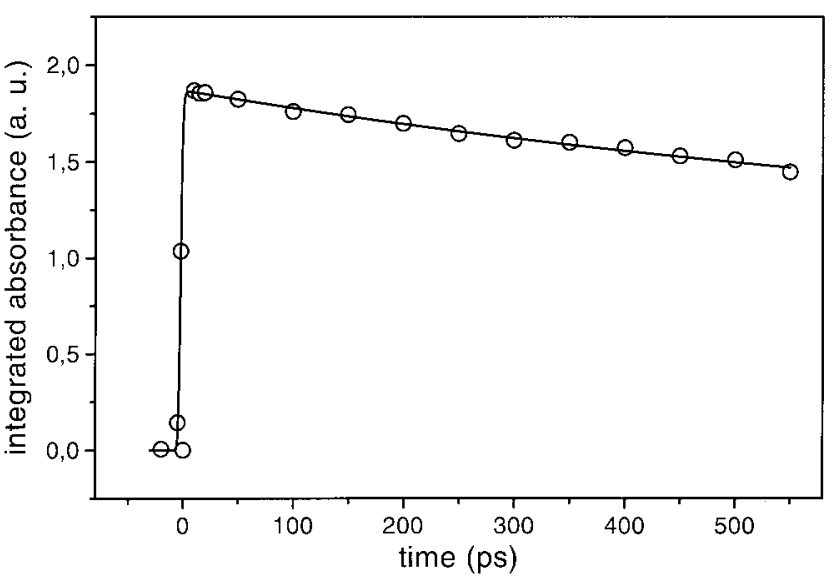

Figure 5. Integrated absorbance of the transient $\mathrm{CO}_{2}$ band as a function of time after excitation of $\mathbf{1}$.

An instantaneous rise is followed by a slow decrease. The latter may be due to some temperature dependence of $B$, with the vibrational intensity being higher in vibrationally hot $\mathrm{CO}_{2}$. The signal clearly shows that $\mathrm{CO}_{2}$ is produced instantaneously upon excitation and that no subsequent decarboxylation can be identified, at least on a time scale up to $0.5 \mathrm{~ns}$. In particular, no concentration change with a time constant of about $55 \mathrm{ps}$ is seen. The data shows that the decomposition of $\mathbf{1}$ occurs either in a concerted manner, according to mechanism 2 , or via mechanism 1 with the $\mathrm{MeFlC}(\mathrm{O}) \mathrm{O} \cdot$ radical decomposing very rapidly within the $1.8 \mathrm{ps}$ time resolution of our setup. Thus, we cannot confirm the results of Falvey and Schuster ${ }^{10}$ derived from VIS probe measurements following excitation at $266 \mathrm{~nm}$. Very recent UV pump/IR probe measurements with our equipment, after modification to excitation at $248 \mathrm{~nm}$, also show the instantaneous fast rise of the $\mathrm{CO}_{2}$ concentration (as in Figure 5). The photochemical behavior thus seems to be independent of the excitation wavelength. ${ }^{25}$ Moreover, variation of the UV pump pulse intensity by a factor of 4 had no detectable influence on the observed "instantaneous" decarboxylation and clearly showed that only one-photon excitation takes place. It should be mentioned that our experimental setup was used recently to study the photofragmentation of tert-butylperoxy-2-naphthyl carbonate. In these experiments a $\mathrm{CO}_{2}$ formation time constant of about 30 ps was observed. ${ }^{26}$

Zewail and co-workers recently reported the femtosecond dynamics of Norrish type I reactions using fs resolved TOF mass spectrometry. ${ }^{27-29}$ They concluded that the $\alpha$-bond cleavage of ketones occurs by a stepwise mechanism in less than a picosecond. In view of these results, an ultrafast stepwise decomposition of 1 within about 1.8 ps cannot be ruled out.

An important question concerns the fraction of $\mathrm{CO}_{2}$ produced on the picosecond time scale relative to the amount of $\mathrm{CO}_{2}$ found after longer time. We measured, also with our spectrometer, the amount of $\mathrm{CO}_{2}$ produced up to several minutes after the excitation. The absorption spectra show that the majority (above $80 \%$ ) of $\mathrm{CO}_{2}$ is formed within the first $1.8 \mathrm{ps}$.

The spectral shifting and narrowing of the $\mathrm{CO}_{2}$ absorption feature (Figure 2a) may be interpreted by energy relaxation via anharmonic coupling, ${ }^{30,31}$ of vibrationally excited low-frequency modes at 672 and $1351 \mathrm{~cm}^{-1}$ with the higher frequency asymmetric stretching mode. According to this assumption, the temporal evolution of the transient spectra in Figure 3 may be used to estimate the cooling rate. Obviously rather extended times are required, which is probably due to the lack of highfrequency modes in the vibrational spectrum of the solvent $\mathrm{CCl}_{4}{ }^{32}$ Aspects related to energy relaxation will be discussed in a forthcoming paper. ${ }^{33}$

In conclusion, the photodecomposition of $\mathbf{1}$ primarily occurs via concerted or ultrafast consecutive bond scission within a couple of picoseconds in contrast to the 55 ps appearance time constant of the methylfluorene radical observed by Falvey and Schuster. ${ }^{10}$ The asymmetric stretching mode of the $\mathrm{CO}_{2}$ photoproduct recorded immediately after the dissociation is spectrally shifted and broadened because of vibrational excitation. During the cooling process, by energy transfer to the solvent, the shape of the absorption band changes over a few hundred picoseconds.

Acknowledgment. The authors thank Prof. J. Troe for his continued commitment and the Deutsche Forschungsgemeinschaft for financial support of this study within the Sonderforschungsbereich 357 ("Molekulare Mechanismen unimolekularer Prozesse”). They are also grateful to AKZO NOBEL for kindly providing the peroxyester and to the referee for valuable suggestions.

\section{References and Notes}

(1) Hiatt, R.; Acyl Peroxides. In Organic Peroxides; Swern, D.; Ed.; Wiley-Interscience: New York, 1971; Vol. II.

(2) Patai, S. The Chemistry of Peroxides; John Wiley and Sons: New York, 1983

(3) Sawaki, Y. Peroxy Acids and Peroxy Esters. In Organic Peroxides; Ando, W., Ed.; John Wiley and Sons: New York, 1992.

(4) Bartlett, P. D.; Hiatt, R. R. J. Am. Chem. Soc. 1958, 80, 1398.

(5) Bartlett, P. D.; Hiatt, R. R. J. Am. Chem. Soc. 1960, 80, 1753.

(6) Pryor, W. A.; Smith, K. J. Am. Chem. Soc. 1970, 92, 5403.

(7) Koenig, T.; Wolf, R. J. Am. Chem. Soc. 1969, 91, 2574.

(8) Neuman, R. C.; Behar, J. V. J. Am. Chem. Soc. 1969, 91, 6024

(9) Chateauneuf, J.; Lusztyk, J.; Ingold, K. U. J. Am. Chem. Soc. 1988 110, 2886.

(10) Falvey, D. E.; Schuster, G. B. J. Am. Chem. Soc. 1986, 108, 7419

(11) Wang, J.; Tateno, J.; Sakuragi, H.; Tokumaru, K. J. Photochem Photobiol. A 1995, 92, 53.

(12) Chateauneuf, J.; Lusztyk, J.; Ingold, K. U. J. Am. Chem. Soc. 1988, $110,2877$.

(13) Misawa, H.; Sawabe, K.; Takahara, S.; Sakuragi, H.; Tokumaru, K. Chem. Lett. $1988,357$.

(14) Rauk, A.; Yu, D.; Armstrong, D. A. J. Am. Chem. Soc. 1994, 116, 8222.

(15) Cunliffe-Jones, D. B. Spectrochim. Acta A 1969, 25, 779.

(16) Aschenbrücker, J.; Steegmüller, U.; Ernsting, N. P.; Buback, M.; Schroeder, J.; Jasny, J. Appl. Phys. B 1997, 65, 441.

(17) Szatmári, S.; Schäfer, F. P. Appl. Phys. B 1988, 46, 305

(18) Jasny, J. Opt. Commun. 1985, 53, 238.

(19) Jasny, J. Rev. Sci. Instrum. 1986, 57, 1303.

(20) Steinberg, M.; Davies, W. O. J. Chem. Phys. 1961, 34, 1373.

(21) Tourin, R. H. J. Opt. Soc. Am. 1961, 51, 175.

(22) Ferriso, C. C. J. Chem. Phys. 1962, 37, 1955.

(23) Buback, M.; Schweer, J.; Tups, H. Z. Naturforsch. 1986, 41a, 505

(24) Buback, M.; Schweer, J.; Tups, H. Z. Naturforsch. 1986, 41a, 512.

(25) Buback, M.; Ernsting, N. P.; Schroeder, J.; Steegmüller, U.; Kling, M. To be published.

(26) Aschenbrücker, J.; Buback, M.; Ernsting, N. P.; Schroeder, J.; Steegmüller, U. Ber. Bunsenges. Phys. Chem. 1998, 102, 000.

(27) Kim, S. K.; Pedersen, S.; Zewail, A. H. J. Chem. Phys. 1995, 103 , 477.

(28) Kim, S. K.; Zewail, A. H. Chem. Phys. Lett. 1996, 250, 279.

(29) Kim, S. K.; Guo, J.; Baskin, J. S.; Zewail, A. H. J. Phys. Chem. 1996, 100,9202 .

(30) Herzberg, G. Molecular Spectra and Molecular Structure. II. Infrared and Raman Spectra of Polyatomic Molecules; Van Nostrand Reinhold: New York, 1945.

(31) Hamm, P.; Ohline, S. M.; Zinth, W. J. Chem. Phys. 1997, 106, 519.

(32) Elsaesser, T.; Kaiser, W. Annu. Rev. Phys. Chem. 1991, 42, 83.

(33) Buback, M.; Ernsting, N. P.; Kling, M.; Schroeder, J.; Steegmüller, U. Chem. Phys. Lett., in preparation. 